\title{
An efficient method for the production of marker-free transgenic plants of peanut (Arachis hypogaea $\mathrm{L}$.)
}

\author{
Madhurima Bhatnagar · Kalyani Prasad • \\ Pooja Bhatnagar-Mathur • M. Lakshmi Narasu • \\ Farid Waliyar · Kiran K. Sharma
}

Received: 9 November 2009/Revised: 12 February 2010/Accepted: 17 February 2010/Published online: 9 March 2010

(c) Springer-Verlag 2010

\begin{abstract}
Recombinant genes conferring resistance to antibiotics or herbicides are widely used as selectable markers in plant transformation for selecting the primary transgenic events. However, these become redundant once the transgenic plants have been developed and identified. Although, there is no evidence that the selectable marker genes are unsafe for consumers and the environment, it would be desirable if the marker genes can be eliminated from the final transgenic events. The availability of efficient transformation methods can enable the possibility of developing transgenic events that are devoid of the marker gene/s upfront. Taking advantage of the high and consistent transformation potential of peanut, we report a technique for developing its transgenics without the use of any selectable marker gene. Marker-free binary vectors harboring either the phytoene synthase gene from maize (Zmpsy1) or the chitinase gene from rice (Rchit) were constructed and used for Agrobacterium tumefaciensmediated transformation of peanut. The putative transgenic events growing in vitro were initially identified by PCR
\end{abstract}

Communicated by P. Kumar.

M. Bhatnagar and K. Prasad contributed equally.

M. Bhatnagar - K. Prasad - P. Bhatnagar-Mathur · F. Waliyar .

K. K. Sharma ( $\square)$

Genetic Transformation Laboratory, International Crops

Research Institute for the Semi-Arid Tropics (ICRISAT),

Patancheru 502324, Andhra Pradesh, India

e-mail: k.sharma@cgiar.org

M. Bhatnagar $\cdot$ K. Prasad · M. Lakshmi Narasu Department of Biotechnology, Jawaharlal Nehru Technological University (JNTU), Kukatpally, Hyderabad 500072,

Andhra Pradesh, India and further confirmed for gene integration and expression by dot blots assays, Southern blots, and RT-PCR where they showed a transformation frequency of over $75 \%$. This system is simple, efficient, rapid, and does not require the complex segregation steps and analysis for selection of the transgenic events. This approach for generation of markerfree transgenic plants minimizes the risk of introducing unwanted genetic changes, allows stacking of multiple genes and can be applicable to other plant species that have high shoot regeneration efficiencies.

Keywords Arachis hypogaea - Groundnut .

Marker-free transgenics · Peanut · Transgenic plants

\section{Introduction}

Genetic transformation of peanut or groundnut (Arachis hypogaea $\mathrm{L}$.) for various biotic and abiotic constraints has been an important area of research (Bhatnagar-Mathur et al. 2008). In a typical plant transformation process, marker genes are used mainly for the initial screening of the putative transgenic shoots to identify the transformed plants from the untransformed ones. Selectable marker genes are conditionally dominant genes that confer an ability to grow in the presence of applied selective agents that are normally toxic to plant cells or inhibitory to plant growth, such as antibiotics and herbicides, e.g., bar, pat, aroA (or epsps), csrl (or ahas), nptII, hemL, hppd and hpt (Aragao and Brasileiro 2002). However, in view of the biosafety requirements, it is recommended to phase out the selectable marker genes since these are unnecessary once an intact transgenic plant has been identified and established (Ow 2001; Puchta 2003; Darbani et al. 2007). Besides, there are public concerns about the widespread 
occurrence of selectable marker genes in novel ecosystems as these are integrated into the plant genome along with gene of interest (Daniell 2002). In addition to the risk of horizontal gene transfer, there is also a "vertical crossspecies" transfer risk that could potentially create enhanced weediness problems in some cases, especially the outcrossing plant species (Dale et al. 2002). Moreover, both pleiotropic and position effects can lead to unpredictable changes in the transgenic plants (Miki et al. 2009). Interaction between the selectable marker gene or its regulatory element and the genetic element at the site of insertion may result in position effects, leading to improper expression or knock-out mutations, induction of genesilencing and chromatin remodeling (Kim et al. 2007). Using selectable marker genes also poses the potential concern of metabolic drain, since the expression of a marker gene and its regulatory element in a transgenic plant often utilizes a significant amount of the host cell's resources, and placing a metabolic load on the host which may dramatically alter biochemistry and physiology of the transgenics (Glick 1995). Furthermore, these may cause regulatory difficulties for approving transgenic crop release and commercialization.

The development of marker-free transgenic plants could thus solve the issues of biological and biosafety in the genetically engineered (GE) crops, besides supporting multiple transformation cycles for transgene pyramiding (Vaucheret et al. 1998). Several strategies that have been used for the elimination of selectable markers include cotransformation, multi-auto-transformation system (MAT), site-specific recombination system, transposon-based marker methods, intrachromosomal recombination system and transplastomics (Miki and McHugh 2004; Darbani et al. 2007). However, these methods involve multiple steps and are time consuming, besides seriously reducing the efficiencies of stable transformants. There have been earlier reports on using binary vectors devoid of selection marker gene for genetic transformation in crops such as potato (de Vetten et al. 2003), alfalfa (Popelka et al. 2003; Rosellini et al. 2007), apple (Malnoy et al. 2007), wheat (Doshi et al. 2007) and tobacco ( $\mathrm{Li}$ et al. 2009) where the recovery of transformed events has been low in the range of $0.93-25 \%$. Although, several reports on regeneration and transformation using selectable markers have been published in peanut, the highest regeneration and transformation efficiency was reported by Sharma and Anjaiah (2000) using cotyledon explants. In the present study, this protocol was further exploited to generate clean transgenic plants of peanut. The system has been tested with two gene constructs where the transgenic plants were recovered at high frequencies. The system provides a novel way of generating marker-free transgenics, especially in an edible crop like peanut.

\section{Materials and methods}

Plant material

For all the experimental procedures on peanut transformation, the cultivar JL 24, a medium duration Spanish type variety was used. The cotyledon explants from presoaked mature seeds were used for the development of transgenic plants. All the conditions used for tissue culture and co-cultivation with Agrobacterium tumefaciens were as described previously (Sharma and Anjaiah 2000; Sharma and Bhatnagar-Mathur 2006).

\section{Construction of binary vectors}

Binary vector pCAMBIA2300 was used as the backbone for construction of plasmids for A. tumefaciens-mediated genetic transformation. To construct the plasmid suitable for marker-free transformation, the $800 \mathrm{bp}$ of $n p t I I$ gene fragment was removed from the plasmid pCAMBIA2300 by restricting with $X h o I$ and was re-ligated to obtain the vector pCAMBIA2300 $\varphi n p t \mathrm{II}$. Two different binary plasmids were then constructed, each with a different gene of interest, viz., rice chitinase (Rchit) and maize phytoene synthase (Zmpsy1).

The $1.57 \mathrm{~kb}$ DNA fragment carrying the $1.1 \mathrm{~kb}$ Rchit from rice genomic clone along with the CaMV $35 \mathrm{~S}$ promoter was recovered from the HindIII digested plasmid pCAMBIA1302:Rchit. This $1.57 \mathrm{~kb}$ DNA fragment was subsequently cloned into the HindIII site of the linearized plasmid pCAMBIA2300 fragment carrying a $1.2 \mathrm{~kb}$ Zmpsy 1 gene driven by the Arabidopsis thaliana oleosin promoter was recovered from the BamHI digested plasmid pCAMBIA2300:oleopsy1. This DNA fragment was cloned into the BamHI site of the linearized plasmid pCAMBIA2300 DNA products were then introduced into Escherchia coli strain DH5 $\alpha$. The orientation and alignment of the fused fragments in the new plasmid were confirmed by restriction analysis and polymerase chain reaction (PCR) with appropriate primers. The selected plasmids were designated as pCAMBIA2300 pCAMBIA2300 $\varphi n p t I I: o l e o p s y 1$ (Fig. 1b), respectively. The modified binary plasmids were introduced into the disarmed Agrobacterium tumefaciens strain C58 through electroporation.

\section{Genetic transformation}

Agrobacterium-mediated genetic transformation of peanut as reported earlier (Sharma and Anjaiah 2000; Sharma and Bhatnagar-Mathur 2006) was employed for the development of transgenic plants. During the whole process of 

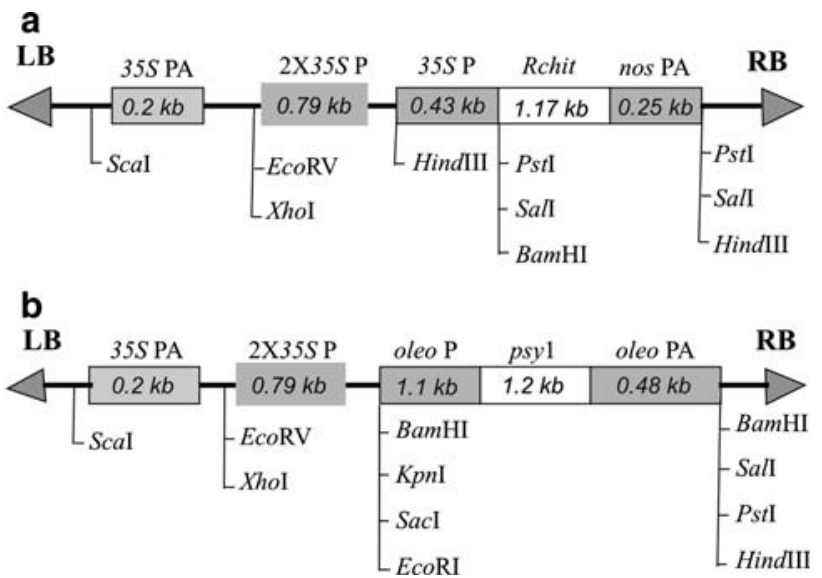

Fig. 1 Schematic representation of the T-DNAs used for peanut transformation without the marker gene. a The T-DNA region of pCAMBIA2300 $\varphi n p t I I$ :Rchit used to introduce the rice Rchit. b The T-DNA region of pCAMBIA2300 pnptII:oleopsy1 used to introduce a phytoene synthase (Zmpsy1) gene

regeneration, recovery and rooting of the putative transgenic plants, no selection agent was used. To identify the transgenic plants, the genomic DNA from the in vitro growing shoots was subjected to PCR by using the respective gene primer pairs. The control plants were cultured simultaneously to regenerate untransformed control plants. The $\mathrm{T}_{0}$ plants were grown to maturity and seeds harvested to obtain the $T_{1}$ generation. The transgenic plants in $T_{0}$ and $T_{1}$ generations were subjected to molecular analysis. Transformation frequency was calculated as [(number of PCR-positive plants/total number of plants produced) $\times 100]$.

\section{Molecular analysis}

Polymerase chain reaction (PCR)

Initially all the primary transformants in $\mathrm{T}_{0}$ generation were screened by PCR to determine presence of the gene of interest and identify the putative transformants. Genomic DNA was extracted from the putative transgenics plants and untransformed control plants grown in vitro or in the greenhouse following the modified CTAB method (Doyle 1991). $150 \mathrm{ng}$ of RNase-treated DNA was used for PCR with oligonucleotide primers: $5^{\prime}$ CGC TAA GGG CTT CTA CAC CTA C $3^{\prime}$ and 5' AGC TTA TCG ATA CCG TCG ACC T $3^{\prime}$ for the Rchit gene and $5^{\prime}$ CGG CTT TAG AGA GAG AAT TGA GAG G $3^{\prime}$ and $5^{\prime}$ TCT TCG TCT TGA GCA GGG TGG AGC 3' were used for Zmpsy1 gene. The PCR reaction was performed in a $25 \mu$ reaction mixture containing $150 \mathrm{ng}$ of genomic DNA, $1 \times$ PCR buffer (10× PCR buffer: $200 \mathrm{mM}$ Tris $\mathrm{HCl}, 500 \mathrm{mM} \mathrm{KCl}$ ), $1.5 \mathrm{mM} \mathrm{MgCl}_{2}, 0.2 \mathrm{mM} \mathrm{dNTP}$ mix, $10 \mathrm{pM}$ of primer I,
$10 \mathrm{pM}$ of primer II, and $1 \mathrm{U}$ of Taq DNA polymerase (Invitrogen ${ }^{\circledR}$ ). The total volume was made up to $25 \mu$ with sterile distilled water. The amplification reactions were carried out using a gradient thermal cycler (Eppendorf ${ }^{\circledR}$ ). The PCR conditions included an initial denaturation at $95^{\circ} \mathrm{C}$ for $5 \mathrm{~min}$ for 1 cycle followed by 35 cycles of denaturation at $95^{\circ} \mathrm{C}$ for $1 \mathrm{~min}$, annealing at $60^{\circ} \mathrm{C}$ (Rchit) or $63.4^{\circ} \mathrm{C}$ (Zmpsy1) for $1 \mathrm{~min}$, and extension at $72^{\circ} \mathrm{C}$ for $1 \mathrm{~min}$, with a final extension at $72^{\circ} \mathrm{C}$ for $10 \mathrm{~min}$. The amplified PCR products were analyzed under UV light following their electrophoresis on $1.2 \%$ agarose gel for the detection of 814 bp Rchit and 663 bp Zmpsy1 amplification fragments.

\section{RT-PCR}

RT-PCR analysis of the putative transformants $\left(\mathrm{T}_{0}\right)$ was carried out using the Thermoscript RT-PCR system (Invitrogen, Carlsbad, Calif.) on total RNA isolated with TRIzol reagent (Invitrogen) according to the manufacturer's protocol using the above-mentioned oligonucleotide primers and PCR conditions.

Southern hybridization and dot blot analysis with the genomic DNA

Genomic DNA was isolated from the leaves of the putative transgenic peanut plants carrying the Rchit gene using the procedure described by Dellaporta et al. (1983). The genomic DNA (20-25 $\mu \mathrm{g})$ was digested with HindIII to release the integrated T-DNA and was separated on a $0.8 \%$ (w/v) agarose gel followed by its transfer to a positively charged nylon membrane (Roche Molecular Biochemicals $\left.^{\circledR}\right)$. Similarly, dot blot assay was performed on Zmpsy1 carrying peanut transgenic samples prepared by boiling the genomic DNA for 10 min that was denatured with $1 \mathrm{M}$ $\mathrm{NaOH}$. The denatured DNA was loaded onto nitrocellulose membrane. A non-radioactive DIG-based system (Roche Molecular Biochemicals ${ }^{\circledR}$ ) was used for conducting prehybridization, hybridization, washing, and detection of the membranes following the manufacturer's protocol. The $1.57 \mathrm{~kb}$ rice Rchit coding sequence was used as probe for Southern analysis, whereas, for dot blot analysis a $1.2 \mathrm{~kb}$ Zmpsy1 coding sequence was used as probe. For autoradiography, the blots were exposed to X-Omat film (Eastman Kodak Company, Rochester, NY, USA) for 15-30 min.

\section{Results and discussion}

Plant transformation

The optimized plant regeneration and transformation system using cotyledon explants of peanut was reliable, 
reproducible, efficient and capable of producing independently transformed plants directly through organogenesis via the development of multiple shoots without any callus phase. The regeneration frequencies ranged from 32 to $48 \%$ which is lower than what we observed in our previous studies with peanut where the regeneration frequency was over 75\% (Sharma and Anjaiah 2000; Sharma and Bhatnagar-Mathur 2006). It is assumed that this could be due to the nature of the transgenes and the promoters used in these studies. However, the average transformation frequencies in both the previous and the present studies ranged between 55 (Sharma and Anjaiah 2000) to $77 \%$ (Table 1). Survival rate of the in vitro regenerated plants was over $90 \%$ and about 30 and 60 putative transgenic plants transformed with Zmpsy1 and Rchit genes, respectively, were transferred to the greenhouse (Table 1). Molecular analysis of $\mathrm{T}_{0}$ and $\mathrm{T}_{1}$ plants through PCR, RT-PCR, Southern blot and dot blot analyses proved the existence of transgenes and absence of selectable marker in the transformants. It is interesting to note that in our ongoing studies on the genetic transformation of other legumes including pigeonpea and chickpea, the transformation efficiency in the former using the marker-free system was as good as peanut (Sharma et al., unpublished results). However, the transformation efficiency was much lower $(\sim 35 \%)$ in the latter species (Sharma et al., unpublished results). These observations indicate that the success of this marker-free system in different crops lies in the robustness of the regeneration protocol besides the amenability of the tissues to Agrobacterium.

\section{Polymerase chain reaction (PCR) and RT-PCR}

Out of 30 oleo:psyl transformants $\left(\mathrm{T}_{0}\right), 23$ were found to be positive for the amplification of the $663 \mathrm{bp}$ fragment of the Zmpsy1 gene (Fig. 2a), while of the 60 transformants carrying 35S:Rchit $\left(\mathrm{T}_{0}\right)$, 45 were found to be positive for the amplification of $814 \mathrm{bp}$ Rchit fragment by PCR
(Fig. 2b). No amplification was observed in DNA from the untransformed control plants. The transformation efficiency using Zmpsy1 and Rchit in the $\mathrm{T}_{0}$ transformants was over 75\%. The expression of Rchit and Zmpsy1 gene in the $\mathrm{T}_{0}$ plants was analyzed by RT-PCR where out of the 45 PCR-positive $\mathrm{T}_{0}$ plants, only 20 plants tested positive for Rchit gene and out of the 6 PCR-positive $\mathrm{T}_{0}$ plants tested, 4 plants were positive for Zmpsy 1 gene (Fig. 3a, b). Nine events carrying Zmpsy1 gene and five events carrying the Rchit gene from $\mathrm{T}_{0}$ generation when advanced to $\mathrm{T}_{1}$ generation showed inheritance and segregation of the introduced genes in a 3:1 Mendelian ratio (Table 2) based on amplification of Zmpsy1 gene and Rchit gene in $\mathrm{T}_{1}$ generation plants (Fig. 4a, b).

\section{Southern hybridization and dot blot analysis}

PCR-positive events were analyzed by Southern blot hybridization and dot blot assay using $1.57 \mathrm{~kb}$ Rchit and $1.2 \mathrm{~kb}$ Zmpsy 1 fragment, respectively, as probes to determine the T-DNA integration. Southern blot analysis of nine selected events indicated the integration of Rchit gene in three events, viz., 18, 32 and 70. No hybridization signal was detected in the untransformed control plants (Fig. 5a). Dot blot assay was performed with nine selected events using denatured genomic DNA $(10 \mu \mathrm{g})$ where five events, viz., C, E, F, G, T showed integration of the transgene (Fig. 5b).

The antibiotic resistance genes have gained importance in selecting the transformants from the non-transformants in the process of producing transgenic plants. Since these are used only as a tool of selection and do not code for any desirable traits, their presence in the transgenic plants is not only unnecessary but may disturb the genetic constituency of the plant and its wild varieties in some cases. Therefore, gene products need to be assessed for safety and environmental impact (Bryant and Leather 1992; Gressel 1992). In view of this, it is necessary to look for alternatives for safer

Table 1 Frequency of recovery of marker-free transgenic plants of peanut by using cotyledonary explants from three separate experiments with

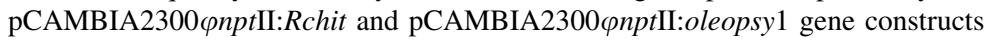

\begin{tabular}{|c|c|c|c|c|c|c|}
\hline Expl no. & Gene & $\begin{array}{l}\text { Number } \\
\text { of explants }\end{array}$ & $\begin{array}{l}\text { Independent events } \\
\text { recovered post } \\
\text { selection }\end{array}$ & $\begin{array}{l}\text { Regeneration frequency } \\
\text { of transformants post } \\
\text { selection }(\%)\end{array}$ & $\begin{array}{l}\text { PCR/RT-PCR } \\
\text { positives }\end{array}$ & $\begin{array}{l}\text { Transformation } \\
\text { frequency }(\%)\end{array}$ \\
\hline 1 & Rchit & 50 & 20 & 40 & 12 & 60 \\
\hline 2 & Rchit & 50 & 22 & 44 & 17 & 77 \\
\hline 3 & Rchit & 50 & 18 & 36 & 16 & 88 \\
\hline 4 & Zmpsy1 & 25 & 8 & 32 & 8 & 100 \\
\hline 5 & Zmpsy 1 & 25 & 10 & 40 & 7 & 70 \\
\hline 6 & Zmpsy1 & 25 & 12 & 48 & 8 & 66 \\
\hline \multicolumn{6}{|c|}{ Mean primary transformants obtained } & 77 \\
\hline
\end{tabular}

Transformation frequency was determined on the basis of PCR analysis of the independent transformants 


\section{a}

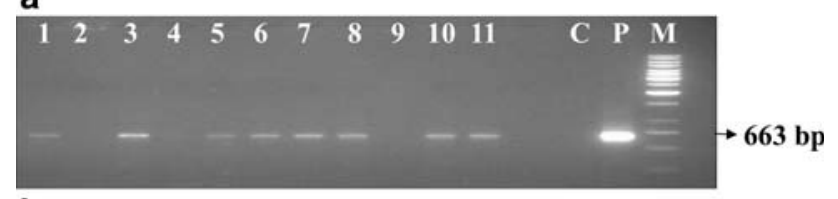

b

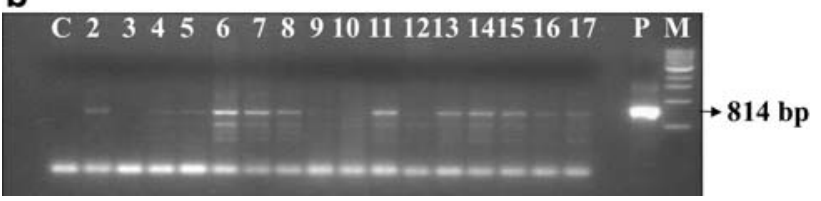

Fig. 2 PCR analysis for Zmpsy 1 and Rchit gene in $\mathrm{T}_{0}$ transformants of peanut. a Lanes $1-11$ carry samples from putative transformants with Zmpsy1 gene, $C$ untransformed control, $P$ pCAMBIA2300 $\varphi n p t I I$ : oleopsy 1 plasmid as positive control, $M 1 \mathrm{~kb}$ molecular weight marker, and arrow indicates a fragment of approximately $663 \mathrm{bp}$. b Lanes $2-17$ carry samples from putative transformants with Rchit gene, $C$ untransformed control, $P$ pCAMBIA2300 $\varphi n p t I I$ :Rchit plasmid as positive control, $M 1 \mathrm{~kb}$ molecular weight marker, and arrow indicates a fragment of approximately $814 \mathrm{bp}$

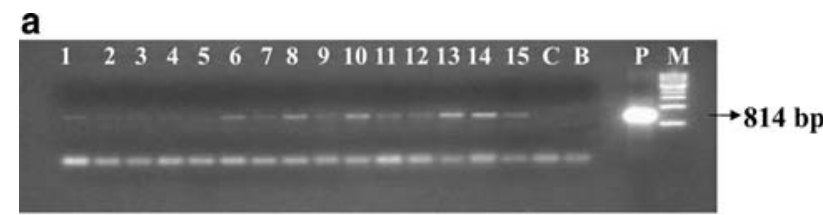

b

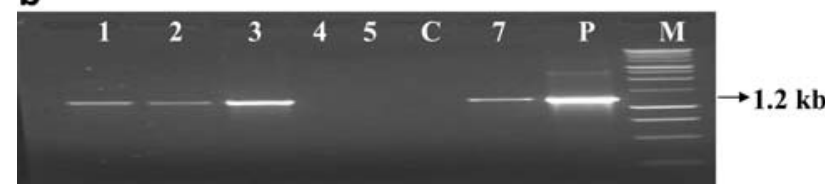

Fig. 3 RT-PCR analysis for Rchit and Zmpsy1 gene in $\mathrm{T}_{0}$ transformants of peanut. a Lanes $1-15$ carry samples from putative transformants, $C$ untransformed control, $P$ pCAMBIA2300 $\varphi n p t \mathrm{II}$ : Rchit plasmid as positive control, $M 1 \mathrm{~kb}$ molecular weight marker, and arrow indicates a fragment of approximately $814 \mathrm{bp}$. b Lanes 1-7 carry samples from putative transformants, $B$ blank, $P$ pCAMBIA2300 pnptII:oleopsy 1 plasmid as positive control, $M 1 \mathrm{~kb}$ molecular weight marker, and arrow indicates a fragment of approximately $1.2 \mathrm{~kb}$

marker genes or elimination of the marker genes from transgenic plants to produce environmentally safe transgenic plants and pyramid a number of transgenes by repeated transformation (Yoder and Goldsbrough 1994). Most alternatives are still in their development phase and are not widely available.

Here we report for the first time, the production of marker-free transgenic plants of peanut with such high transformation efficiency (over 75\%). This study avoids the introduction of antibiotic resistance marker genes in plant cells, thus eliminating the risk of horizontal gene transfer, if any, and also mitigating vertical gene transfer. Our method is free from negative effects of selective agents that can limit the ability of transgenic cells to proliferate and differentiate into transgenic plants. In the present study,
Table 2 Inheritance of the Zmpsy1 or Rchit gene in the respective $\mathrm{T}_{1}$ generation progeny of transgenic peanut carrying marker-free construct pCAMBIA2300pnptII having either the Zmpsy1 or Rchit gene

\begin{tabular}{|c|c|c|c|c|c|}
\hline \multirow[t]{2}{*}{ Event\# } & \multirow[t]{2}{*}{ Gene } & \multirow{2}{*}{$\begin{array}{l}\text { Total no. of } \mathrm{T}_{1} \\
\text { plants tested } \\
\text { per event }\end{array}$} & \multicolumn{2}{|c|}{$\begin{array}{l}\text { PCR analysis } \\
\text { of the transgene }\end{array}$} & \multirow[t]{2}{*}{$\chi^{2} 3: 1$} \\
\hline & & & $+v e$ & $-\mathrm{ve}$ & \\
\hline A & Zmpsy 1 & 9 & 7 & 2 & 0.037 \\
\hline B & Zmpsy 1 & 7 & 4 & 3 & 1.190 \\
\hline $\mathrm{C}$ & Zmpsy1 & 14 & 12 & 2 & 0.857 \\
\hline $\mathrm{D}$ & Zmpsy 1 & 6 & 6 & 0 & 2.000 \\
\hline $\mathrm{E}$ & Zmpsy 1 & 5 & 3 & 2 & 0.600 \\
\hline $\mathrm{F}$ & Zmpsy 1 & 4 & 4 & 0 & 1.330 \\
\hline G & Zmpsy 1 & 14 & 11 & 3 & 0.095 \\
\hline $\mathrm{H}$ & Zmpsy 1 & 7 & 4 & 3 & 1.190 \\
\hline $\mathrm{J}$ & Zmpsy1 & 3 & 3 & 0 & 1.000 \\
\hline 18 & Rchit & 14 & 12 & 2 & 0.860 \\
\hline 32 & Rchit & 16 & 14 & 2 & 1.330 \\
\hline 70 & Rchit & 15 & 13 & 2 & 1.090 \\
\hline 75 & Rchit & 13 & 11 & 2 & 0.640 \\
\hline 77 & Rchit & 15 & 13 & 2 & 1.090 \\
\hline
\end{tabular}

$\chi^{2}$ for $P=5 \%$ is 3.84

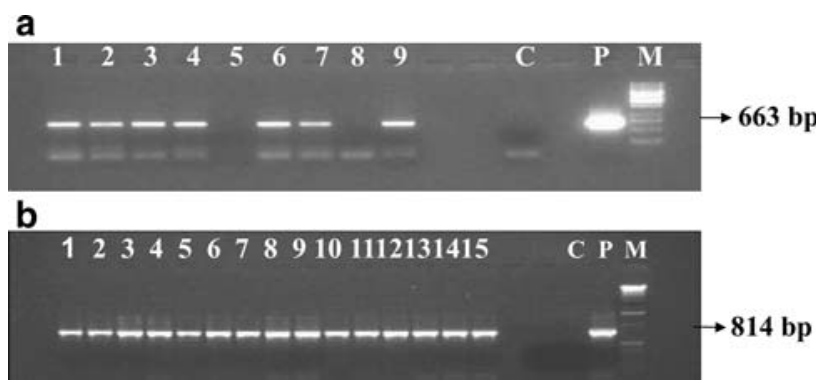

Fig. 4 PCR analysis for Zmpsy1 and Rchit gene in $\mathrm{T}_{1}$ progenies of independent transgenic events of peanut. a Lanes $1-9$ carry samples from putative transformants with Zmpsy1 gene, $C$ untransformed control, $P$ pCAMBIA2300 trol, $M 1 \mathrm{~kb}$ molecular weight marker, and arrow indicates a fragment of approximately $663 \mathrm{bp}$. b Lanes $1-15$ carry samples from putative transformants with Rchit gene, $C$ untransformed control, $P$ pCAMBIA2300 $\varphi n p t \mathrm{II}:$ Rchit plasmid as positive control, $M 1 \mathrm{~kb}$ molecular weight marker, and arrow indicates a fragment of approximately $814 \mathrm{bp}$

plants were regenerated through direct organogenesis pathway using Agrobacterium-mediated gene transfer from cotyledon explants that involves a very short regeneration phase of 2-3 weeks only as reported earlier by Sharma and Anjaiah (2000). Direct regeneration systems have advantages due to the rapidity of morphogenesis and lack of frequent subcultures, besides an extremely rapid and synchronous de novo production of shoots (Bhatnagar-Mathur et al. 2008). Recently, $\mathrm{Li}$ et al. (2009) reported a nonselection approach for tobacco transformation where the 
a

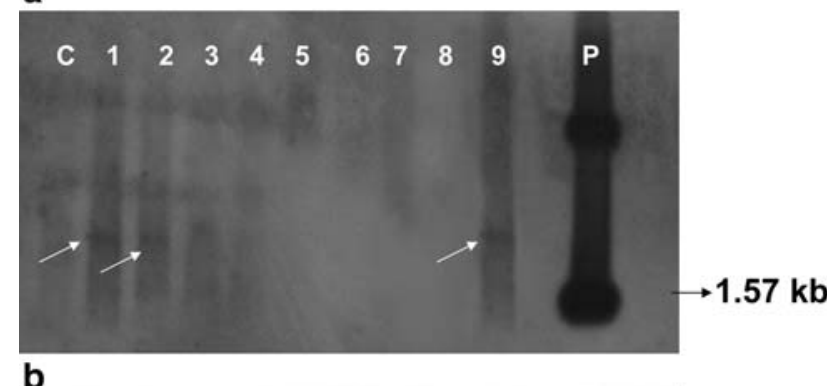

b

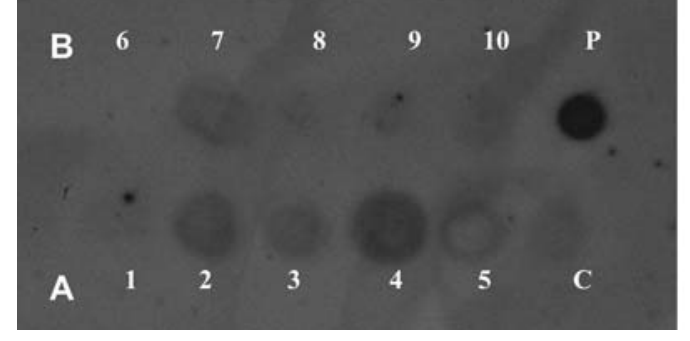

Fig. 5 Southern and dot blot analysis of primary transformants of peanut. a Southern blot analysis using the genomic DNA digested with HindIII enzyme to release the integrated T-DNA region and probed with $1.57 \mathrm{~kb}$ Rchit. Lanes 1,2, and 9 carry sample from events 18,32 and 70 and lanes $3-8$ carry sample from events $15,16,56,77$, 75, and 72, $C$ untransformed control, $P$ pCAMBIA2300 pnptII:Rchit plasmid restricted with HindIII to release the $1.57 \mathrm{~kb}$ Rchit gene fragment. b Dot blot assay of transformants carrying Zmpsy1 gene, probed with $1.2 \mathrm{~kb} Z m p s y 1$ coding sequence fragment. Lane A: 1-5 carry samples from events $\mathrm{K}, \mathrm{G}, \mathrm{F}, \mathrm{E}$, and $\mathrm{C}$, and lane $B$ : 6-10 carry samples from events $\mathrm{S}, \mathrm{T}, \mathrm{L}, \mathrm{M}$, and N. $C$ untransformed control, $P$ pCAMBIA2300

transformation efficiency was quite low. However, in our study with peanut, the transformation efficiency obtained is comparable to that reported earlier using the selectable marker system (Sharma and Anjaiah 2000; Sharma and Bhatnagar-Mathur 2006). In these studies, all the shoots arising from one explant were considered as a single event; however, upon molecular characterization, these differed in the gene integration pattern, and hence the efficiency could be much higher than what was reported $(55 \%)$.

In the previously reported studies using non-antibiotic methods for producing transgenic plants, the efficiency obtained from these studies has been very low where the frequency of marker-free transgenic plants was $2.22 \%$ in rye (Popelka et al. 2003), $4.5-5 \%$ in potato (de Vetten et al. 2003), $6.25 \%$ in potato (Ahmad et al. 2008), 22-25\% in apple (Malnoy et al. 2007), $1.55 \%$ in wheat and $0.93 \%$ in triticale (Doshi et al. 2007), 15\% in tobacco (Jia et al. 2007), $7 \%$ in alfalfa (Weeks et al. 2008) and 2.8\% in tobacco ( $\mathrm{Li}$ et al. 2009). In contrast, the transformation efficiency reported here is the highest (over $75 \%$ ) so far and is also comparable to frequencies obtained using the selectable marker system (Sharma and Anjaiah 2000; Sharma and Bhatnagar-Mathur 2006). This could be attributed to the highly efficient regeneration and transformation protocol used in this study. Besides, the earlier reports show no data on stable transmission of transgene into progenies using non-antibiotic approach for the development of marker-free transgenic (De vetten et al. 2003; Jia et al. 2007), whereas our study demonstrated expression and integration of transgene into progenies and Mendelian inheritance of the transgenes similar to results obtained by Li et al. (2009).

Our method for producing marker-free plants possesses several advantages as compared to other approaches such as co-transformation (Dutt et al. 2008), recombinase systems (Gleave et al. 1999; Zuo et al. 2001; Arumugam et al. 2007), transposase driven system (Goldsbrough et al. 1993), intrachromosomal recombination system, multi-auto transformation (MAT) vector system (Saelim et al. 2009) in terms of having a single step process without involving the genetic segregation and having less chances of producing chimeras. The phenomenon of chimerism due to incomplete DNA excision has also been reported (Gleave et al. 1999; Sugita et al. 1999; Zuo et al. 2001; Schaart et al. 2004). Moreover, transposon excision, recombinasebased methods and intrachromosomal recombination methods are more prone to somaclonal variations and lead to genomic instability in transgenic plants (Scutt et al. 2002; Darbani et al. 2007). Also, the efficiency of transposon-based system is low due to tendency of transposable elements to insert elsewhere in genome. Besides, the expression of microbial recombinases for prolonged periods in plant cells may result in unwanted changes to the genome at sites removed from transgene insertions (Scutt et al. 2002). Although, the isopentenyl transferase (ipt) gene has been used as a selectable marker for transformation of many plant species (Ebinuma and Komamine 2001), the system was not very efficient, and the use of the ipt selectable marker may require the optimization of transformation protocols due to changes in tissue culture conditions. The advantages of the present method over the previously reported ones are as follows:

1. No selection pressure is required during the transformation process and PCR analysis is done to distinguish transformed from the untransformed shoots/plants. Taking into account the labor involved in this approach, Popelka et al. (2003) applied sample pooling strategy to facilitate the identification of marker-free transgenic rye plants by PCR.

2. So far, most of the studies on developing marker-free transgenic plants had used the uidA (GUS) gene for establishing the proof of concept and also in the construct used for final event development (Jia et al. 2007; Weeks et al. 2008). Hence, such reporter gene has a potential to remain in the final selected event. 
However, since our objective was to develop clean transgenic events for practical applications on crop improvement, no reporter gene was included in the transformation vector.

3. This method of producing a high number of independently transformed plants within a short period is applicable to all vegetatively and sexually propagated crops. In contrast, the co-transformation method cannot be used for vegetatively propagated crops as genetic segregation is needed to select the marker-free plants (Scutt et al. 2002). Besides, all recombinase and intrachromosomal recombination method-based systems require sexual crosses for removal of recombinase gene and hence, cannot be used with vegetatively propagated plants (Scutt et al. 2002).

4. A limited number of constitutive promoters are commonly used to express marker genes, and their repeated introduction could activate gene-silencing mechanisms with negative effects on the expression of one or more transgenes of interest (Puchta 2003). Therefore, a marker-free transformation system proves to be better option for multiple gene pyramiding.

In conclusion, marker free-based transformation system reported in this paper is highly reproducible and did not require further optimization of regeneration protocol, including the use of hormones or antibiotic selection, and could also very well be applied to other economically important crops for which efficient regeneration protocols are available. This is the first report on the development of marker-free (both selectable and reportable) transgenic peanuts using an one-step procedure. This technique has a potential for generating clean transgenic peanut plants with economically important traits. Besides, absence of selectable marker genes would circumvent the need to confirm the biosafety of these genes; thereby, facilitating the development of a regulatory approval package and also lower the costs for commercial release of new genetically modified products (Kuiper et al. 2001; Daniell 2002; Smyth et al. 2002).

Acknowledgments We acknowledge the financial support from HarvestPlus, the global Challenge Program on Biofortification for part of this work. MB and KP would like to thank the Jawaharlal Nehru Technological University (JNTU), Hyderabad, India for providing an opportunity to register for Ph.D. program. The excellent assistance by the technical staff of the Genetic Transformation laboratory at ICRISAT is duly acknowledged.

\section{References}

Ahmad R, Kim YH, Kim MD, Phung MN, Chung WI, Lee HS, Kwak SS, Kwon SY (2008) Development of selection marker-free transgenic potato plants with enhanced tolerance to oxidative stress. J Plant Biol 51:401-407
Aragao FJL, Brasileiro ACM (2002) Positive, negative and markerfree strategies for transgenic plant selection. Braz J Plant Physiol 14:1-10

Arumugam N, Gupta V, Jagannath A, Mukhopadhyay A, Pradhan AK, Burma PK, Pental D (2007) A passage through in vitro culture leads to efficient production of marker-free transgenic plants in Brassica juncea using the Cre/loxP system. Transgenic Res 16:703-712

Bhatnagar-Mathur P, Anjaiah V, Kirti PBK, Sharma KK (2008) Agrobacterium-mediated genetic transformation of peanut. In: Kirti PBK (ed) Handbook of new technologies for genetic improvement of legumes. CRC Press, USA, pp 227-251

Bryant J, Leather S (1992) Removal of selectable marker genes from transgenic plants: needless sophistication or social necessity. Trends Biotechnol 10:274-275

Dale PJ, Clarke B, Fontes EMG (2002) Potential for the environmental impact of transgenic crops. Nat Biotechnol 20:567574

Daniell H (2002) Molecular strategies for gene containment in transgenic crops. Nat Biotechnol 20:581-586

Darbani B, Eimanifar A, Stewart CN, Camargo WN (2007) Methods to produce marker-free transgenic plants. Biotechnol J 2:83-90

de Vetten N, Wolters AM, Raemakers K, van der Meer I, ter Stege R, Heeres E, Heeres P, Visser R (2003) A transformation method for obtaining marker-free plants of a cross pollinating and vegetatively propagated crop. Nat Biotechnol 21:439-442

Dellaporta SJ, Wood J, Hicks JB (1983) A plant DNA minipreparation: version II. Plant Mol Biol Rep 4:19-21

Doshi KM, Eudes E, Laroche A, Gaudet D (2007) Anthocyanin expression in marker free transgenic wheat and triticale embryos. In Vitro Cell Dev Biol -Plant 43:429-435

Doyle JJ (1991) DNA protocols for plants-CTAB total DNA isolation. In: Hewitt GM, Johnston A (eds) Molecular techniques in taxonomy. Springer, Berlin, pp 283-293

Dutt M, Li ZT, Dhekney SA, Gray DJ (2008) A co-transformation system to produce transgenic grapevines free of marker genes. Plant Sci 175:423-430

Ebinuma H, Komamine A (2001) MAT (multi-auto-transformation) vector system. The oncogenes of Agrobacterium as positive markers for regeneration and selection of marker-free transgenic plants. In Vitro Cell Dev Biol Plant 37:103-113

Gleave AP, Mitra DS, Mudge SR, Morris BAM (1999) Selectable marker-free transgenic plants without sexual crossing: transient expression of cre recombinase and use of a conditional lethal dominant gene. Plant Mol Biol 40:223-235

Glick BR (1995) Metabolic load and heterologous gene expression. Biotechnol Adv 13:247-261

Goldsbrough AP, Lastrella CN, Yoder JI (1993) Transposition mediated re-positioning and subsequent elimination of marker gene from transgenic tomato. Biotechnol 11:1286-1292

Gressel J (1992) Indiscriminate use of selectable markers-sowing wild oats? Trends Biotechnol 10:382

Jia H, Liao M, Verbelen JP, Vissenberg K (2007) Direct creation of marker-free tobacco plants from agroinfiltrated leaf discs. Plant Cell Rep 26:1961-1965

Kim SI, Veena, Gelvin SB (2007) Genome-wide analysis of Agrobacterium T-DNA integration sites in the Arabidopsis genome generated under non-selective conditions. Plant $\mathbf{J}$ 51:779-791

Kuiper HA, Kleter GA, Noteborn HPJM, Kok EJ (2001) Assessment of the food safety issues related to genetically modified foods. Plant J 27:503-528

Li B, Xie C, Qiu H (2009) Production of selectable marker-free transgenic tobacco plants using a non-selection approach: chimerism or escape, transgene inheritance, and efficiency. Plant Cell Rep 28:373-386 
Malnoy M, Borejsza-Wysocka EE, Abbott P, Lewis S, Norelli JL, Flaishman M, Gidoni D, Aldwinckle HS (2007) Genetic transformation of apple without use of a selectable marker. Acta Hortic 738:319-322

Miki B, McHugh S (2004) Selectable marker genes in transgenic plants: applications, alternatives and biosafety. J Biotechnol 107:193-232

Miki B, Abdeen A, Manabe Y, MacDonald P (2009) Selectable marker genes and unintended changes to the plant transcriptome. Plant Biotechnol J 7:211-218

Ow DW (2001) The right chemistry for marker gene removal? Nat Biotechnol 19:115-116

Popelka JC, Xu J, Altpeter F (2003) Generation of rye (Secale cereale L.) plants with low transgene copy number after biolistic gene transfer and production of instantly marker-free transgenic rye. Transgenic Res 12:587-596

Puchta H (2003) Marker-free transgenic plants. Plant Cell Tissue Org Cult 74:123-134

Rosellini D, Capomaccio S, Ferradini N, Sardaro MLS, Nicolia A, Veronesi F (2007) Non-antibiotic, efficient selection for alfalfa genetic engineering. Plant Cell Rep 26:1035-1044

Saelim L, Phansiri S, Suksangpanomrung M, Netrphan S, Narangajavana J (2009) Evaluation of a morphological marker selection and excision system to generate marker-free transgenic cassava plants. Plant Cell Rep 28:445-455

Schaart JG, Krens FA, Pelgrom KTB, Mendes O, Rouwendal GJA (2004) Effective production of marker-free transgenic strawberry plants using inducible site-specific recombination and a bifunctional selectable marker gene. Plant Biotechnol J 2:233-240

Scutt CP, Zubko E, Meyer P (2002) Techniques for the removal of marker genes from transgenic plants. Biochimie 84:1119-1126

Sharma KK, Anjaiah V (2000) An efficient method for the production of transgenic plants of peanut (Arachis hypogaea L.) through Agrobacterium tumefaciens-mediated genetic transformation. Plant Sci 159:7-19

Sharma KK, Bhatnagar-Mathur P (2006) Peanut (Arachis hypogaea L.). Methods in Mol Biol 343:347-358

Smyth S, Khachatourians GG, Phillips PWB (2002) Liabilities and economics of transgenic crops. Nat Biotechnol 20:537-541

Sugita K, Matsunaga E, Ebinuma H (1999) Effective selection system for generating marker-free transgenic plants independent of sexual crossing. Plant Cell Rep 18:941-947

Vaucheret H, Beclin C, Elmayan T, Feuerbach F, Godon C, Morel JB, Mourrain P, Palauqui JC, Vernhettes S (1998) Transgeneinduced gene silencing in plants. Plant J 16:651-659

Weeks JT, Ye J, Rommens CM (2008) Development of an in planta method for transformation of alfalfa (Medicago sativa). Transgenic Res 17:587-597

Yoder JI, Goldsbrough AP (1994) Transformation system for generating marker-free transgenic plants. Biotechnology 12:263-267

Zuo J, Niu QW, Moller SG, Chua NH (2001) Chemical-regulated, site-specific DNA excision in transgenic plants. Nat Biotechnol 19:157-161 